This item was submitted to Loughborough's Institutional Repository (https://dspace.lboro.ac.uk/) by the author and is made available under the following Creative Commons Licence conditions.

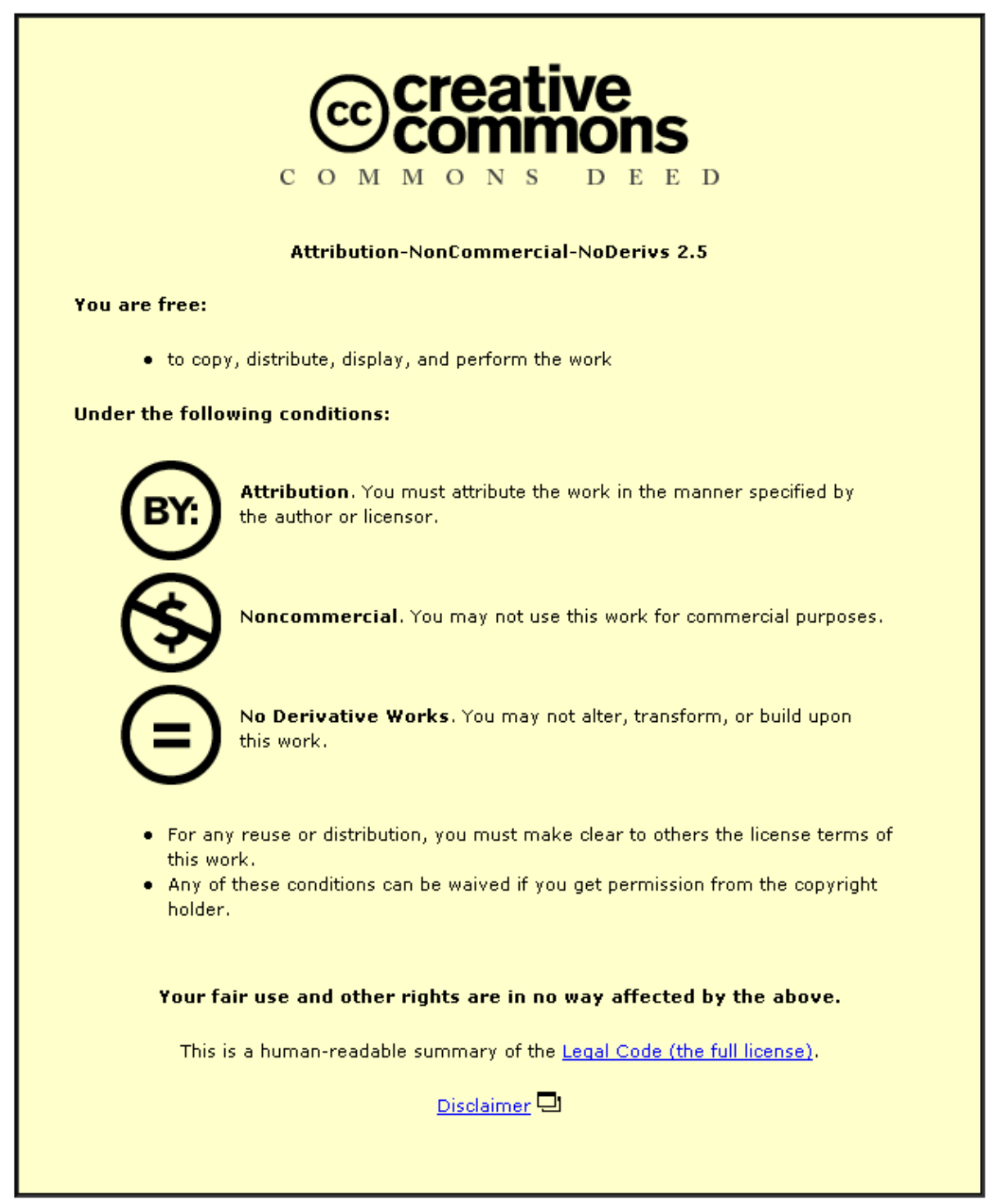

For the full text of this licence, please go to: http://creativecommons.org/licenses/by-nc-nd/2.5/ 


\title{
Relative age effect in Spanish association football: Its extent and implications for wasted potential
}

\author{
Idafe Pérez Jiménez and Mathew T.G. Pain \\ School of Sport and Exercise Sciences, Loughborough University, United Kingdom
}

\begin{abstract}
Spain is one of the largest and most successful powers in international youth football, but this success has not extended to the national team. This lack of continued success seems to indicate a loss of potential. Relative age effect has been detected in football across many countries. Understanding the extent of this bias in the youth teams of Spanish elite clubs may help to improve selection processes and reduce the waste of potential. Comparisons between players from: the Spanish Professional Football League, all age categories of these clubs' youth teams, the U17-U21 national teams, the national team and the Spanish population, show a constant tendency to under-represent players from the later months of the selection year at all age groups of youth and U17 to U21 national teams. Professional and national team players show a similar but diminished behaviour that weakens with aging, which suggests that talent identification and selection processes can be improved to better identify potential talent early on and minimise wasted potential.
\end{abstract}

Talent identification, Selection processes, Soccer, Season of Birth Bias

\section{INTRODUCTION}

In sport and education children are grouped chronologically to promote age related development. In Spain the selection period for education and sport is traditionally established between January $1^{\text {st }}$ and December $31^{\text {st }}$ : a child born on the first day of this period would therefore be a year older than one born on the last day, but will still compete in the same category every season. The competition in Spanish youth football is structured in two year categories, except the eldest one, which covers up to four years (see Table 1). In most cases clubs have at least an A and a B team, comprised of final and first year players respectively. Except for exceptional cases, who stand out and are moved up, players tend to be in a team with others born the same year.

The relative age effect arises from the inevitable difference in physical, emotional and intellectual development between the oldest and the youngest children in a group. A large body of research has reported relative age effect worldwide in many sports and in academia (Musch \& Grondin 2001). In youths a year's difference can lead to a significant variation in anthropometrical variables (height, weight...), development of physical condition (strength, speed...), cognitive skills (reflected in game analysis, perception, tactical ability or strategy) or psychological/emotional maturity (Blanksby, Bloomfield, Elliot, Aclkland \& Morton, 1986; Fenzel, 1992; Helsen, Hodges, Van Winckel \& Starkes, 2000; Reilly, Bangsbo \& Franks, 2000; Simmons \& Paull, 2001; Philippaerts et al., 2006). Other benefits for early developers may be a years more experience and what Helsen, van Winckel \& Williams (2005) call the initial performance advantage. The initial performance advantage consists of positive external and self-feedback, linked to the perceived increased competence due to relative age effect, that can increase motivation and therefore short term 
performance. For late borns, perception of failure can increase the drop-out rate in the youngest players (Helsen, Starkes \& van Winckel, 1998).

Maturational age, as opposed to chronological, should be the factor to be considered (MacPhail, 2005). Biological maturation seems to be an important factor in selection processes. A tendency in elite clubs to select players with an advanced biological maturation has been reported (Malina et al. 2007a, Malina et al. 2007b), and is reasonable to link that preference with the advantages provided by maturity in the functional capacity and skills of players (Malina et al. 2004, Malina et al. 2005). In adolescents, the range in variation of skeletal age for a given chronological age is likely to exceed 2 years (Malina 2007b): between an early-born early maturer and a late-born late maturer a chronological year may imply a vast maturational difference. It is however obvious that in the same age group, on average, players born early in the year are more likely to be more developed than those born at the end of the year.

Many efforts have been dedicated to assess what variables appear to define toplevel athletes (and elite footballers in particular): psychological/sociological, like motivational orientation, competitive anxiety or anticipation skills (Fenzel, 1992; Helsen et al., 1998; Morris, 2000; Cumming, Battista, Standage, Ewing \& Malina, 2006); technical/motor control, like passing, shooting, controlling, dribbling or perception/visualization tasks (Helsen \& Starkes, 1999; Davids, Lees \& Burwitz, 2000; Williams, 2000); and physical/anthropometrical, like strength, speed, agility, flexibility, endurance, speed, somatotype or body composition (Reilly et al., 2000; Helsen et al., 2000; Philippaerts et al., 2006; Bloomfield, Polman \& O'Donoghue, 2007). Elite sport is not characterized by an equal opportunities policy. Clubs selecting young players aim mainly at winning in the short term or at feeding higher levels of the club with home made players. The first option responds to image reasons: trying to appear as a "successful" club at all stages; the second aims at nurturing players within the club's ethos, playing style or philosophy, providing better opportunity to make it to the first team.

Spanish football has been remarkably successful in youth football, with titles including: two U21, six U19 and seven U17 European Championships; one U20 World Cup; four of the seven Meridian Cups (U18 from Europe and Africa); one gold and two silver medals in Olympic Games; and six Maurice Burlaz Trophies, which UEFA awards to the Association with most successful results in the youth sector. All this makes Spain, in terms of youth teams, the largest power in European football and one of the most successful in the world. However, this has not extended to the national team which has only managed a single fourth place in the World Cup and a single win and a single runner-up position in the European Championship. This seems like a weak performance compared with their youth. Regarding the two aims mentioned above, it seems that Spanish youth football works better at promoting itself than it does in generating top-level players for the national team.

Although relative age effect is unlikely to account on its own for the difference in performance between the Spanish national team and its youth national teams, relative age effect has been consistently described in several countries as a probable cause of the potential waste of upcoming players (Simmons \& Paull, 2001; Helsen, van Winckel \& Williams, 2005; Vaeyens, Philippaerts \& Malina, 2005). This research investigates the extent of relative age effect in Spanish elite youth teams, its variation across clubs and through all age categories and its propagation to professional and international level, and tries to assess the implications for wasted potential created by 
this bias. It was hypothesized that relative age effect would be notorious in the youth teams of professional clubs, escalating in the U17 to U21 national teams and influencing the access of youth players to the professional level.

\section{METHODS}

The first data set included 1012 players (age at 1-Jan-07 26.9 $44.8 \mathrm{y} / \mathrm{o}$ ) from the 42 teams of Spanish Liga de Fútbol Profesional (LFP) which covers the two highest divisions, Primera and Segunda. This group includes $~ 99 \%$ of all first teams players, or players that have played LFP with a reserve team license, before the winter transfer window (source: Liga de Fútbol Profesional registry). The data for each player included date of birth, nationality and position (goalkeeper / defender / midfielder / striker). Where appropriate, non-Spanish players were screened out for the calculations. The second data set contained 2053 players $(14.9 \pm 2.6 \mathrm{y} / \mathrm{o}, \sim 35 \%$ of the total) from 109 youth teams of 17 LFP clubs (source: individual Clubs). The sample contained teams from all age groups in which the competition is structured. Data included date of birth, age group (category), team within the age group (A,B,C...) and position.

The third data set consisted of 86 players that participated in international competitions between 2001 and 2007 with the U17 to U21 Spanish national teams (Meridian Cups; FIFA U17 and U20 World Cups; UEFA U17, U19 and U21 Championships). The fourth data set contained 56 Spanish players selected for the national team between 2001 and 2007 (source: Real Federación Española de Fútbol).

Table 1. Sample size for the five groups, years that each youth category cover during the 2006/07 season and period of players considered on national teams.

\begin{tabular}{lrl}
\hline Category & Sample & Comment \\
\hline Primera & 494 & LFP highest division \\
Segunda & 518 & LFP second division \\
Total LFP & 1012 & \\
Juvenil & 731 & Born 1987-1990 \\
Cadete & 561 & Born 1991-1992 \\
Infantil & 432 & Born 1993-1994 \\
Alevín & 219 & Born 1995-1996 \\
Benjamín & 110 & Born 1997-1998 \\
Total youth teams & 2053 & \\
U17-21 national teams & 86 & Period 2001-2007 \\
National team & 56 & Period 2001-2007 \\
Spanish population & 4636950 & Born 1987-1998 \\
\hline
\end{tabular}

The monthly distribution of births in Spain between 1987 and 1998 (same years as youth teams players) was used as the control group (source: Instituto Nacional de Estadística). For a simpler comparison of means, a normalized index of the birthday in the year was created $\left(I_{B} \in[0,100] \equiv[1 J a n, 31 D e c]\right] \equiv[$ day 1 , day 365]). Means for all groups (LFP players, Spanish LFP players, youth teams players, national team players, U17 to U21 national teams players and general population) were compared together between all of them with Kruskal-Wallis tests (Fallowfield, Hale \& Wilkinson, 2005, p. 225) and between every pair of groups with a Mann-Whitney U-test (Fallowfield, Hale \& Wilkinson, 2005, pp. 190-193). Distributions in four-months periods were compared with Goodness of Fit tests. The inequality of each distribution was also 
evaluated with the Gini Coefficient $\left(\mathrm{I}_{\mathrm{G}}\right)$ and represented through Lorenz Curves (Parra López et al. 2007, p.67).

Correspondence analyses provide an exploratory method for representing data in an Euclidean space, so that the results can be visually examined for structure. The multivariate treatment of data, through simultaneous consideration of multiple categorical variables, can reveal relationships that would not be detected in paired comparisons (Hair et al. 2006 pp.663, 673-674). Therefore, for LFP players the dependency of distribution in four-months periods was explored for positions, nationality and age through a correspondence analysis, following the method of Jiménez-González \& Ramos Domínguez (2002, pp. 45-70). For youth teams, the dependency was explored for clubs, positions, categories and year (A/B/others/single team for the category)

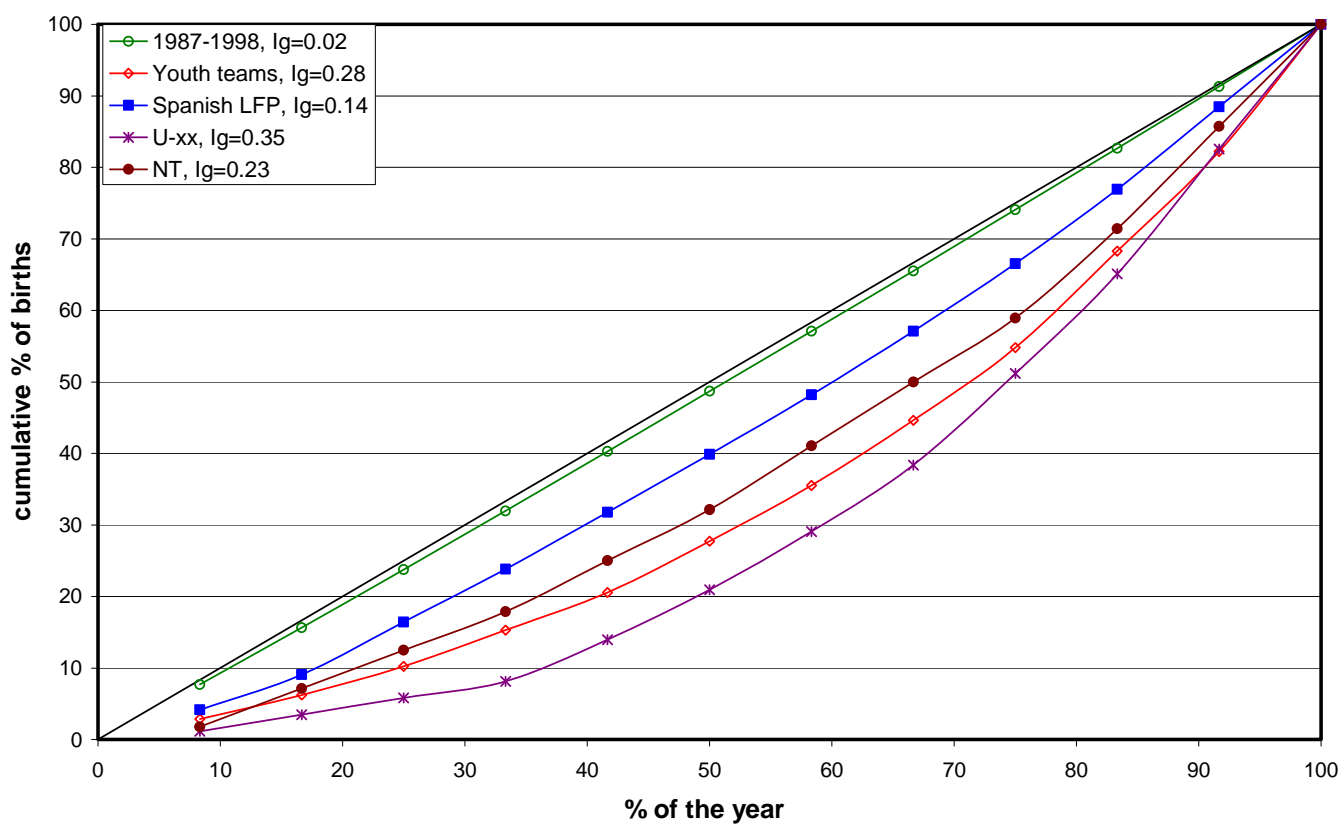

Figure 1. Lorenz curve for each group and the general population. The Gini Index (area between the line and the bisector) for every group is shown in the legend. Straight line, line of perfect equality.

Table 2. Sample size for the five groups, years that each youth category cover during the 2006/07 season and period of players considered on national teams.

\begin{tabular}{lrl}
\hline Category & Sample & Comment \\
\hline Primera & 494 & LFP highest division \\
Segunda & 518 & LFP second division \\
Total LFP & 1012 & \\
Juvenil & 731 & Born 1987-1990 \\
Cadete & 561 & Born 1991-1992 \\
Infantil & 432 & Born 1993-1994 \\
Alevín & 219 & Born 1995-1996 \\
Benjamín & 110 & Born 1997-1998 \\
Total youth teams & 2053 & \\
U17-21 national teams & 86 & Period 2001-2007 \\
National team & 56 & Period 2001-2007 \\
Spanish population & 4636950 & Born 1987-1998 \\
\hline
\end{tabular}




\section{RESULTS}

\section{i. Homogeneity and equality of groups}

As shown in Table 2, youth players have a very similar $\mathrm{I}_{\mathrm{B}}$ to that of $\mathrm{U} 17$ to $\mathrm{U} 21$ national teams players $(p=0.61)$, but are very different from LFP players (both including the whole sample and only Spanish players, $\mathrm{p}=0.00$ ). Youth teams players also have a very different $I_{B}$ when compared with the national team $(p=0.00)$. U17 to U21 national teams players show a significantly different distribution when compared to national team players $(\mathrm{p}=0.001)$. Spanish LFP players and national team players show a very similar $I_{B}(p=0.77)$. Although the inequality is far more noticeable in the national team, in youth teams and especially in U17 to U21 teams than in the LFP, all show a comparatively biased distribution (see Figure 1). There was significant difference $(p<0.05)$ for all variables between every group and the general population, which shows $I_{B}$ and $I_{G}$ values of a virtually homogeneous and equal distribution (see Figures 1 and 2).

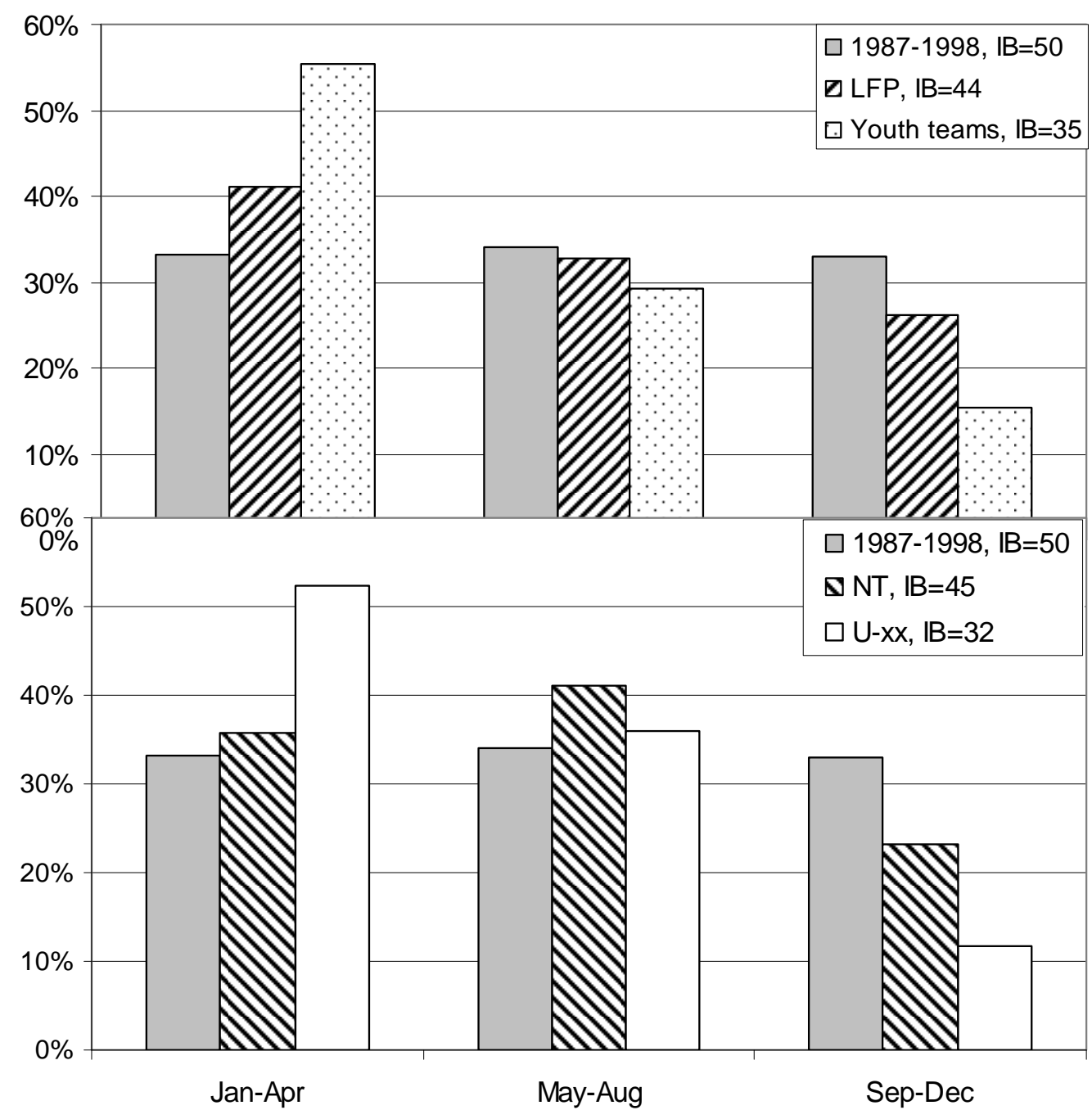

Figure 2. Distribution of birthdays in four-month periods (a) for LFP teams and their youth teams and (b) the national team and the U17 to U21 national teams, both compared with the general population born between 1987 and 1998 (same years as youth players). Legend includes the mean birth index for the group. 


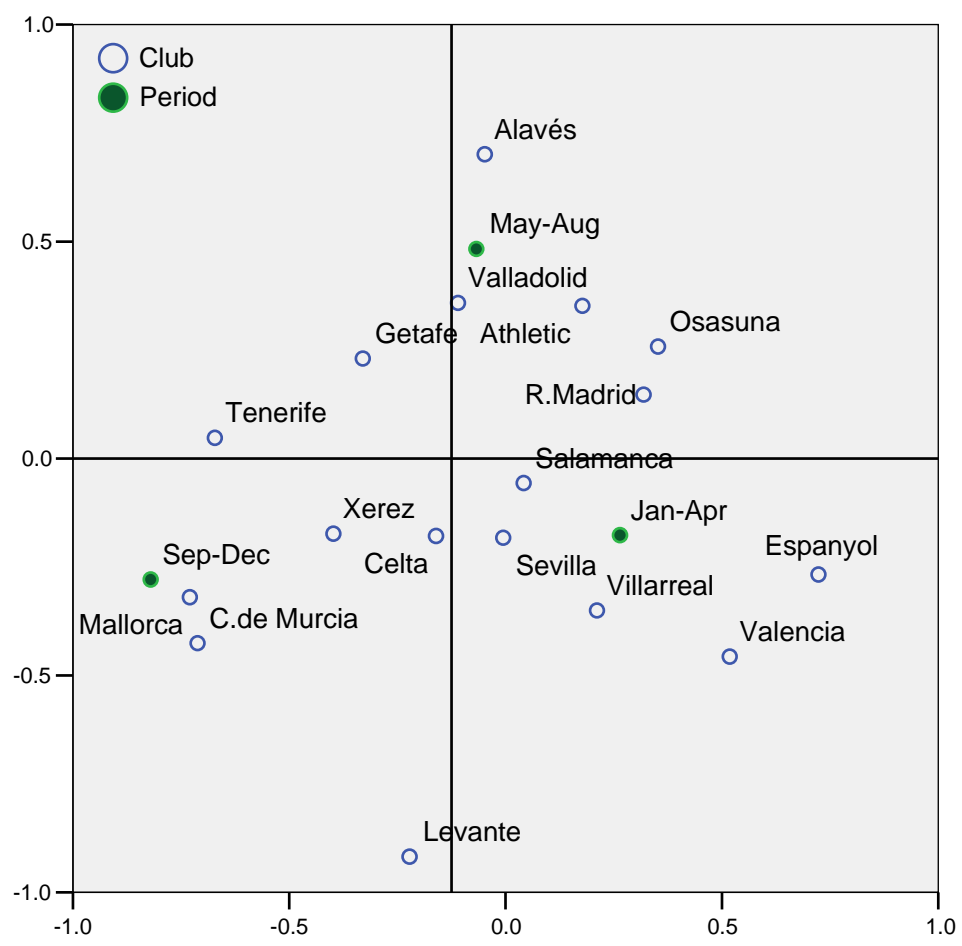

Figure 3. Correspondence analysis for youth teams of LFP clubs. X and Y dimensions correspond to the two synthetic variables that scored highest and second highest respectively, in accounting for $\chi^{2}$ association between categories.

\section{ii. Youth teams and Under-17 to Under-21 national teams players}

For youth players, differences in distribution are not significant for categories $(\mathrm{p}=0.64)$, years $(\mathrm{A} / \mathrm{B} / \mathrm{other}$ team, $\mathrm{p}=0.75)$ or positions $(\mathrm{p}=0.32)$. There is, however, $\mathrm{a}$ dramatic effect in players aged 19 (in the last year of youth football), with $100 \%$ of the sample born between January and April. Although all clubs show manifest relative age effect in their youth teams when compared with the general population $(p<0.05)$, there are significant differences in how heterogeneous the distribution is (e.g. Espanyol: $56 / 26 / 12 / 5, \quad I_{B}=35$; Tenerife: 32/27/26/15, $\left.I_{B}=45 ; \quad p=0.00\right)$. The same example illustrates the two different types of bias that can be observed. Early-borns are clearly favoured only in some cases, such as in Espanyol, but late-borns are disadvantaged in every case. The correspondence analysis points up the differences between the distributions of clubs (see Figure 3). This effect can also be observed in U17 to U21 teams (e.g. the 2002 U19 European Championship squad: 44/28/22/6, $\mathrm{I}_{\mathrm{B}}=31$; only a year later, the 2003 U20 World Cup squad: 35/40/20/5, $\mathrm{I}_{\mathrm{B}}=35 ; \mathrm{p}=0.00$ ).

\section{iii. Liga de Futbol Profesional and national team players}

For LFP players, there is no significant difference when comparing $\mathrm{I}_{\mathrm{B}}$ between Primera and Segunda $(p=0.78)$ or between positions $(p=0.17)$. There is a significant difference in the extent of the effect between nationalities $(p=0.04)$. As illustrated by the correspondence analysis (see Figure 4). Spanish (ESP), Brazilian (BRA), Portuguese (POR) and Uruguayan (URU) players show a clear bias against late-borns. French (FRA) and Argentinean (ARG) also show some inequality, but not a significant 
difference with an homogeneous distribution ( $>>0.05)$. The group of all players of any of the other 32 Nationalities (OTHERS) present in LFP teams has quite an opposite distribution (28/30/42). It is worth noticing that all nationalities with a sample $>10$ (those mentioned above) show to some extent inequality of similar characteristics.

For LFP players there is also a significant difference in the extent of relative age effect between ages of players ( $\mathrm{p}=0.00$ both for the whole sample and only for Spanish LFP players). In particular, 19 y/o players in LFP teams show a very biased distribution (70/22/8). As shown in Figure 5 the birthday index moves from below the mean value for U17 to U21 national teams $\left(\mathrm{I}_{\mathrm{B}}=29\right.$ for ages $\left.<20\right)$ to be almost identical to the general population $\left(\mathrm{I}_{\mathrm{B}}=51\right.$ for $\left.>30\right)$. The correspondence analysis illustrates the shift quite clearly (see Figure 6).

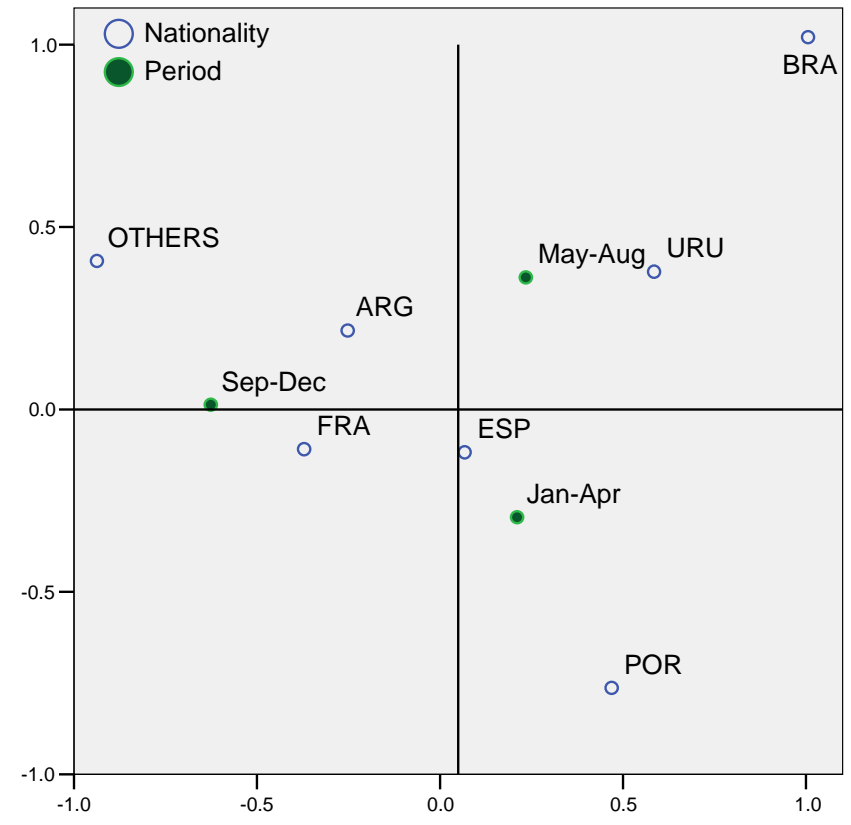

Figure 4. Correspondence analysis for players in LFP teams, between their nationality and the period of birth in the year. $\mathrm{X}$ and $\mathrm{Y}$ dimensions correspond to the two synthetic variables that scored highest and second highest respectively, in accounting for $\chi^{2}$ association between categories.

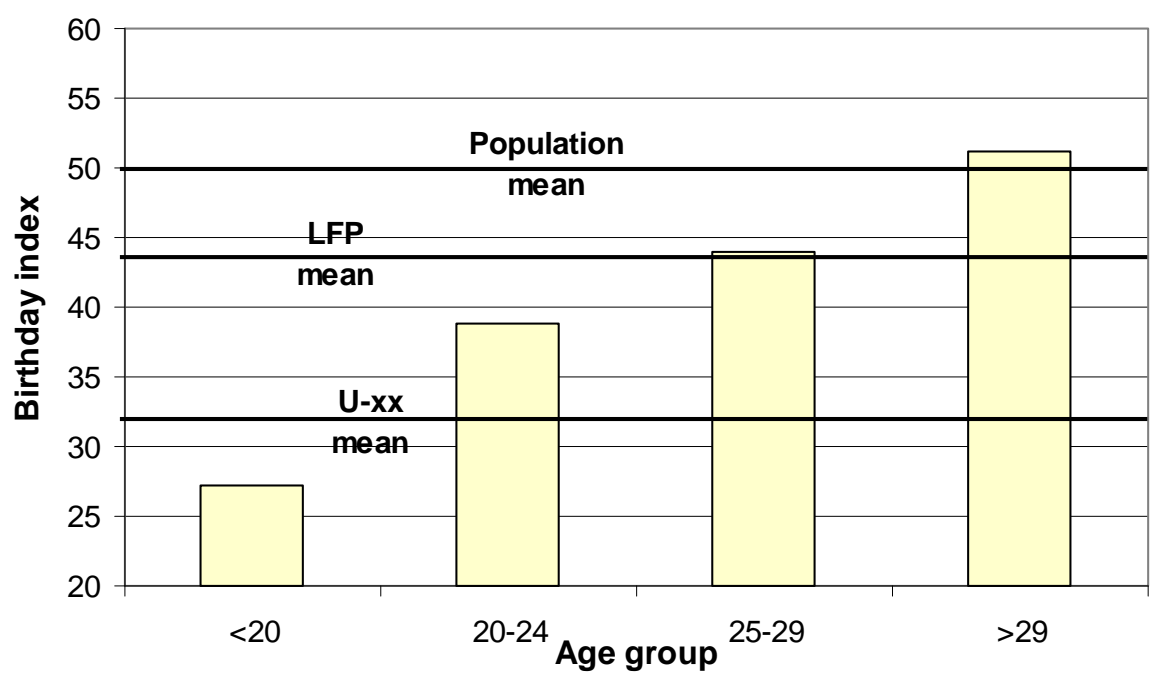

Figure 5 Mean index of birthday $\mathrm{I}_{\mathrm{B}}$ for different age groups in Spanish LFP players. 


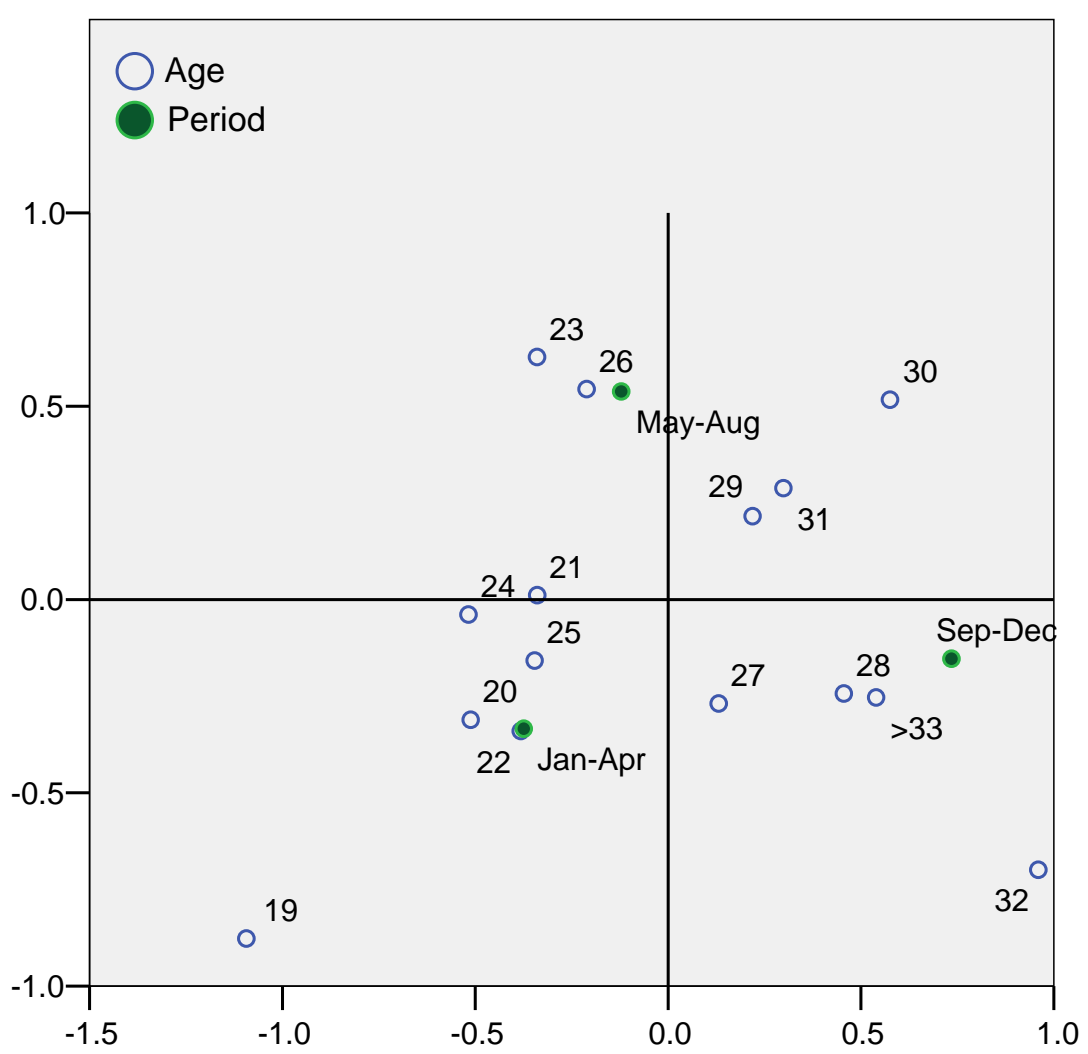

Figure 6. Correspondence analysis for Spanish players in LFP teams between age and period of birth in the year. $\mathrm{X}$ and $\mathrm{Y}$ dimensions correspond to the two synthetic variables that scored highest and second highest respectively, in accounting for $\chi 2$ association between categories.

\section{DISCUSSION}

As shown quite clearly in Table 2 and Figure 2, the relative age efect in Spanish football is evident at all stages, from grassroots to professional levels, corroborating previous research in other countries (Simmons \& Paull, 2001; Helsen et al., 2005). Its extent on LFP is noticeable, and the lack of significant differences between Spanish LFP players and national team players implies the latter are a good representation of the former, but Its huge prevalence in youth teams of these clubs is especially noteworthy. As evident in the current study, players born late in the year suffer a disadvantage even greater that the advantage granted by being born early in the year. In teams where the bias towards early year's favouritism is less pronounced, the players born at the very end of the year are still underrepresented. The accentuated pattern displayed in the Lorenz curves for U17 to U21 national teams (Figure 1) presumably comes from the fact that they are a selection within the selection, and chosen based on competition performance and scouting. If these methods promote bias, their application on already heterogeneous groups will further increase the inequality of distributions. In this sense, it can be said that U17 to U21 national teams are a good portrait of how selection processes operate at grassroots level (there is no significant difference in distribution between both groups).

The absence of significant differences between positions or age categories, beside the sharp accentuation for 19 y/o players, implies a broad generalisation of the problem through all development stages of elite clubs. A dramatic $100 \%$ of players in their last year of youth football were born between January and April. This may arise 
because Juvenil covers four years while Cadete, immediately below, covers only two, creating a bottleneck likely to be dealt with through a new round of selections. Also, last year players are only allowed to participate in the very competitive (and followed) División de Honor Juvenil, which leads to the Spanish Youth Championship title. This restriction is bound to create an even more severe selection.

The fact that all 17 clubs for which youth teams were analysed had relative age effect to some degree denotes its widespread occurrence throughout the country. Although there is a significant difference between each club and the general population, there are also significant differences among them and certain patterns emerge from the correspondence analysis. Two clubs from islands (Tenerife and Mallorca) and two Segunda clubs from small cities (Xerez and Ciudad de Murcia) are the least represented by the Jan-Apr period. Clubs regarded as successful, from big cities and/or with important reputations for their youth teams (like Espanyol, Valencia, Villarreal, Real Madrid and Osasuna) are the ones strongly characterized by the JanApr period. This diversity among clubs seems to relate to the different availability of players, due to geographical constraints, population levels or competition from other elite clubs in the same area. It may also respond to different selection policies, but further research analysing particular clubs in detail would be needed to assess this.

Both professional and national team players show a clearly unequal distribution when compared with the general population, but comparatively less pronounced than youth teams players or U17 to U21 national teams players. For professional players, there seem to be a strong correlation between extent of relative age effect and age. Both Figure 5 and the correspondence analysis for Spanish professional players and age illustrate quite clearly a shift from very low values of the birthday index for players aged $<20$ to be almost identical to the general population for players aged $>30$. Given this re-equilibration of distributions, it can be concluded that once the physical development is completed, and therefore the intrinsic advantages for early-borns are eliminated, players that were left out in early selection processes have a later chance to make it to the elite level. Thus they have succeeded in reaching professional level without the top level training that the selected players presumably enjoyed (it is assumed that top level clubs will provide the best available training) and therefore may have developed their potential to a lesser extent, since according to Howe, Davidson \& Sloboda (2000), "differences in early experiences, preferences, opportunities, habits, training and practice are the real determinants of excellence". Many others may have dropped-out, with valuable potential consequently being lost. A collateral consequence is that many players that enjoyed the advantage of the system may have not met the standards of top level competition. The set of advantages afforded to comparatively more mature players may lead them to place less emphasis in the development of skills required at an elite level. Once at that level, and without the advantages provided by the relative age effect, the lack of those key skills may result in a weaker condition to compete with players that did develop them.

The effect of allegedly talented players that do not meet the standards of elite football once they reach professional level is more evident when comparing the national team and U17 to U21 national teams. Ideally, if the aim was nurturing a potent national team, international level players would have been detected, developed and be competing in U17 to U21 national teams since their early stages. It is statistically improbable that both groups would then observe very different distributions. They are, however, significantly different and therefore seems obvious that U17 to U21 national teams are not a good representation of what the national team 
will be like. These teams are, however, a good diagnosis of how youth elite football looks.

Differences between nationalities of professional players may respond to several factors. Although FIFA unified in 1997 the start date of the selection year for international competitions in 1 January (Helsen et al., 2005), many of the non-Spanish LFP players may have gone through a mixture of selection dates. Another causes can be a lack of structured youth competitions (preventing in fact any relative age effect) or inaccurate records of birthdates, in some of the countries of origin. The relatively small sample for nationalities that show a dissimilar behaviour and their diversity do not allow to reach any conclusions. The existence of inequality of similar characteristics in all nationalities with a sample $>10$ seems to support this.

Assuming that elite clubs provide their youth with the best available training and if the final goal is increasing the quantity and quality of top level players at professional and international level, detecting potential rather than short term performance becomes essential in talent identification. However, procedures are most often carried out through traditional competition and scouting strategies rather than through a research-based approach. This consolidates advantages for eye-catching variables, that are likely to be significant for relative age effect (MacPhail et al., 2005, p.7). The development of more objective, research-based selection procedures and the provision of an optimal environment for nurturing the right skills, can be expected to produce a larger number of first class competitors (Abbott, Collins, Martindale \& Sowerby, 2002). The use of scientific criteria for talent identification offers various advantages: reduced subjectivity; can aim for potential rather than developed talent; reduced time to peak performance, by more effectively selecting gifted individuals and therefore enhancing training effectiveness; increases competitiveness among those selected; improves motivation and self confidence, offering reachable chances to become part of the elite (Abbott et al., 2002, p.2).

Choosing a reliable method is, however, troublesome. Potential is constantly transforming during maturation and one talent may even transmute into other, or be lost, if it is not recognised and developed (Simonton, 1999). Procedures that depend on anthropometrical, fitness or motor control variables may eliminate late maturers with potential, while early maturers with talent are not required to develop technical, tactical or strategic skills, due to the over-emphasized importance of strength, speed or size, until it becomes to late to cultivate them. Considering the results of the present study, that might well be happening in Spanish elite youth football and may be one of the causes for such a different performance between U17 to U21 national teams and the Spanish national team. Furthermore, several studies affirm that early detection through these variables is not possible due to their instability (Blanksby et al., 1986; Bloomfield, Blanksby \& Ackland, 1990). There is also an influence from emotional and intellectual maturation: early maturers are likely to have comparatively more developed cognitive skills, that are translated in finesse, strategy and increased selfconfidence due to his perception of his own performance relative to his team mates (Simmons \& Paull 2001). Having one more year of experience can make the difference to very young players (Helsen et al., 2005) and, as shown, selection starts at an early age. It is therefore essential to distinguish between performance and talent in all these stages (Davids et al., 2000). There is no indication whatsoever that in a developed country the birthday influences the final outcome of any possibly relevant variables once the development period has ended. relative age effect is therefore an artificial consequence of the competition structure and creates a waste of potential. 
The strong negative correlation between age and relative age effect at LFP seems to support this.

Pondering the numerous variables that appear to define an elite athlete (Williams \& Reilly, 2000; Abbott et al., 2002), it is obvious that if there was a reliable method for detecting potential it would be a multidisciplinary and multivariable one, of the sort proposed by Reilly, Williams, Nevill \& Franks (2000). However, identifying these variables is not enough for determining how selection processes are currently carried out and how to improve them. Helsen et al. (2000) suggest that "much of what coaches see as early talent may be explained by physical precocity associated with a relative age advantage" and point that there is a positive correlation between practice and skill. If talent identification is to be improved, finding how elite players were when they were selected becomes more important than learning how they are when they reach the top. Also, assessing selection processes requires identifying in detail how coaches and scouts perceive potential: why, precisely, they decided to select those from amongst many others. Anthropometric characteristics remain obvious candidates, but Simmons \& Paull (2001) point out that even when players are separated in groups attending to body features, the relative age bias remained.

\section{CONCLUSIONS}

Being born just before or just after the cut-off date has opposite and dramatic influence on the chances of being selected by elite clubs for their youth teams and, once there, to be further selected to represent their nation. Selection processes appear to be very biased through the relative age effect. The fact that this effect dilutes with age in professional teams may imply that players with potential are left out only because of later development and therefore presumably enjoy lesser infrastructure to cultivate that potential and achieve the highest possible level. It is hence imperative to analyze what exactly are the variables that catch the eye of coaches and scouts and contrast them with those that really define latent talent and potential. A realistic and useful selection process, free of bias and aiming to maximize the number of top level performers nurtured with the best possible resources, can only be designed after understanding both sides of the coin. However, if the aim is the short-term weekend or season victory, it is obvious that the present system works quite efficiently for Spanish youth football.

\section{REFERENCES}

Abbott, A., Collins, D., Martindale, R. \& Sowerby, K. (2002). Talent Identification and Development: An Academic Review. Edinburgh: sportscotland.

Blanksby, B.A., Bloomfield, J., Elliot, B.C., Ackland, T.R. \& Morton, A.R. (1986). The anatomical and physiological characteristics of pre-adolescent males and females. Australian Paediatric Journal, 22(3), 177-180.

Bloomfield, J., Blanksby, B.A. \& Ackland, T.R. (1990). Morphological and physiological growth of competitive swimmers and non-competitors through adolescence. Australian Journal of Science and Medicine in Sport, 22, 4-12.

Bloomfield, J., Polman, R. \& O'Donoghue, P. (2007). Physical demands of different positions in FA Premier League soccer. Journal of Sports Sciences and Medicine, 6, 63-70.

Cumming, S.P., Battista, R.A., Standage, M., Ewing, M.E. \& Malina, R.M. (2006). Estimated maturity status and perceptions of adult autonomy support in youth soccer players. Journal of Sports Sciences, 24(10), 1039-1046. 
Davids, K., Lees, A. \& Burwitz, L. (2000). Understanding and measuring coordination and control in kicking skills in soccer: implications for talent identification and skill acquisition. Journal of Sports Sciences, 18(9), 703-714.

Fallowfield, J.L., Hale, B.J. \& Wilkinson, D.M. (2005). Using Statistics in Sport and Exercise Science Research. Chichester: Lotus Publishing.

Fenzel, L.M. (1992). The Effect of Relative Age on Self-Esteem, Role Strain, GPA, and Anxiety. The Journal of Early Adolescence, 12(3), 253.

Hair, J.F., Black, W.C., Babin, B.J., Anderson, R.E. \& Tatham, R.L. (2006). Multivariate data analysis. 6th edn. Pearson, New Jersey.

Helsen, W.F., Hodges, N.J., Van Winckel, J. \& Starkes, J.L. (2000). The roles of talent, physical precocity and practice in the development of soccer expertise. Journal of Sports Sciences, 18(9), 727-736.

Helsen, W.F. \& Starkes, J.L. (1999). A multidimensional approach to skilled perception and performance in sport. Applied Cognitive Psychology, 13(1), 1-27.

Helsen, W.F., Starkes, J.L. \& Van Winckel, J. (1998). The influence of relative age on success and dropout in male soccer players. American Journal of Human Biology, 10(6), 791-798.

Helsen, W.F., van Winckel, J. \& Williams, A.M. (2005). The relative age effect in youth soccer across Europe. Journal of Sports Sciences, 23(6), 629-636.

Howe, M.J.A., Davidson, J.W. \& Sloboda, J.A. (2000). Innate talents: Reality or myth? Behavioral and Brain Sciences, 21(03), 399-407.

Jiménez González, V. \& Ramos Domínguez, Á. (2002). Técnicas de análisis multivariante. La Laguna: Campus.

MacPhail, A. e.a. (2005). Talent identification, selection and development. Loughborough: Institute of Youth Sport.

Malina, R.M., Eisenmann, J.C., Cumming, S.P., Ribeiro, B. \& Aroso, J. (2004). Maturity-associated variation in the growth and functional capacities of youth football (soccer) players 13-15 years. European journal of applied physiology, 91(5), 555-562.

Malina, R.M., Cumming, S.P., Kontos, A.P., Eisenmann, J.C., Ribeiro, B. \& Aroso, J. (2005). Maturity-associated variation in sport-specific skills of youth soccer players aged 13-15 years. Journal of sports sciences, 23(5), 515-522.

Malina, R.M., Ribeiro, B., Aroso, J. \& Cumming, S.P. (2007a). Characteristics of youth soccer players aged 13-15 years classified by skill level. British journal of sports medicine, 41(5), 290-295.

Malina, R.M., Chamorro, M., Serratosa, L. \& Morate, F. (2007b). TW3 and Fels skeletal ages in elite youth soccer players. Annals of Human Biology, 34(2), 265272.

Morris, T. (2000). Psychological characteristics and talent identification in soccer. Journal of Sports Sciences, 18(9), 715-726.

Musch, J. \& Grondin, S. (2001). Unequal competition as an impediment to personal development: A review of the relative age effect in sport. Developmental Review, 21(2), 147-167.

Parra López, E., Calero García, F.J., Jiménez González, V., Ramos Domínguez, A.M. \& García González, C.G. (2007). Estadística para turismo. Madrid: Mc Graw Hill Interamericana. 
Philippaerts, R.M., Vaeyens, R., Janssens, M., Van Renterghem, B., Matthys, D., Crae, R., Bourgois, J., Vrijens, J., Beunen, G. \& Malina, R.M. (2006). The relationship between peak height velocity and physical performance in youth soccer players. Journal of Sports Sciences, 24(3), 221-230.

Reilly, T., Bangsbo, J. \& Franks, A. (2000). Anthropometric and physiological predispositions for elite soccer. Journal of Sports Sciences, 18(9), 669-683.

Reilly, T., Williams, A.M., Nevill, A. \& Franks, A. (2000). A multidisciplinary approach to talent identification in soccer. Journal of Sports Sciences, 18(9), 695-702.

Simmons, C. \& Paull, G.C. (2001). Season-of-birth bias in association football. Journal of Sports Sciences, 19(9), 677-686.

Simonton, D.K. (1999). Talent and its development: An emergenic and epigenetic model. Psychological Review, 106(3), 435-457.

Vaeyens, R., Philippaerts, R.M. \& Malina, R.M. (2005). The relative age effect in soccer: a match-related perspective. Journal of Sports Sciences, 23(7), 747-756.

Williams, A.M. (2000). Perceptual skill in soccer: implications for talent identification and development. Journal of Sports Sciences, 18(9), 737-750.

Williams, A.M. \& Reilly, T. (2000). Talent identification and development in soccer. Journal of Sports Sciences, 18(9), 657-667. 